\title{
How does the treadmill affect gait in Parkinson's disease?
}

\author{
Olalla Bello and Miguel Fernández-Del-Olmo
}

\begin{abstract}
Parkinson's disease (PD) is clinically characterized by symptoms of akinesia, rigidity, and resting tremor, which are related to a dopaminergic deficiency of the nigrostriatal pathway. Disorders of gait are common symptoms of PD that affect the quality of life in these patients. One of the main focuses of physical rehabilitation in PD is to improve the gait deficits in the patients. In the last decade, a small number of studies have investigated the use of the treadmill for the rehabilitation of gait in PD patients. Although, the results of these studies are promising, the mechanisms underlying the therapeutic effect of the treadmill in PD are still largely unknown. This paper reviews 10 years of investigation of treadmill training in PD, focusing on the possible mechanisms involved in the therapeutic effect of the treadmill. Understanding these mechanisms may improve the prescription and design of physical therapy programs for PD patients.
\end{abstract}

Keywords:

Gait, mechanisms, Parkinson's disease, physical therapy, treadmill.

\section{Introduction}

The treadmill is a machine for walking or running without displacement. Originally, it was a type of mill operated by animals or persons treading steps on a wheel to grind grain. References of this ancient engine appear around 25 B.C. in the Architecture of Vitruvius, and later in the Codice Atlantico of Leonardo da Vinci and De Re Metallica of Georgius Agricola [1]. In the middle of the XX century, a new motorized treadmill began to be employed in the medical field for ergometry studies [2-4]. Today, the treadmill is a very common device in training centers, gyms, hospitals and investigation centers.

In the physiological field the treadmill has been used to explore the neurophysiology of the locomotion in mammals. Pioneering studies in spinalized cats (at thoracic or at upper lumbar level) showed that these animals could step on the treadmill with their hind-limbs, if their body weight was externally supported. The long-term use of the treadmill, in combination with a gradual reduction in the body weight support (BWS), led to a significant recovery in the locomotion of the cats [5-8]. On the basis of these experiments, the same approach was applied to humans with spinal cord injury [9-14]. A harness that supports a part of their body weight was used in order to keep an erected posture in these patients when they walked over the treadmill.

More recently, the use of the treadmill has been introduced for gait rehabilitation in other neurologic pathologies such as Parkinson's disease (PD).

\section{The role of the treadmill in gait rehabilitation of $\mathrm{PD}$ patients}

Parkinson's disease (PD) is a neurodegenerative disease that affects motor function, from speech to gait. Clinically, the level of functional disability is determined using the UPRDS (Unified Parkinson's Disease Rating Scale) and Hoehn and Yarh (H\&Y) scales [15, 16]. The UPRDS is a rating scale made up of several sections including mentation, behaviour, activities of daily life, and motor evaluation. The H\&Y scale describes how the symptoms of PD progress. The original H\&Y scale included stages 1 through 5 , however stage $0,1.5$ and 2.5 have been added. This modified H\&Y allocates states from 0 to 5 to indicate the relative level of disability in PD patients [15].

PD is clinically characterized by symptoms of akinesia, rigidity, and resting tremor, which are related to a dopaminergic deficiency of the nigrostriatal pathway. However, gait disorders are among the most significant impairments in PD, greatly affecting the quality of life in these patients [17, 18]. Gait in PD 
patients is characterized by a decrease in stride length when compared to age-matched healthy subjects. This is often accompanied by a reduced gait speed, an increase of the double support phase and of the stride variability [19-26]. Postural instability and gait disorders can predispose PD patients to falls. Whereas traditional measures of gait and postural control cannot adequately predict falls in PD [27], increased stride variability has been associated with the risk of falls in aging people and in PD patients [28-31].

Pharmacological therapy is effective in the early stages of the disease. However, as the disease progresses, gait disorders worsen, leading to start hesitation, freezing episodes and an increase in the risk of falls [32, 33]. Thus, improving gait disorders is crucial in the rehabilitation of PD patients [25, 34].

In the last decade, the treadmill has become a therapeutic tool for gait rehabilitation in PD patients. Several studies reported promising results but the true therapeutic potential of treadmill training and the mechanisms underlying these benefits remain uncertain.

\subsection{Acute Effects of a Treadmill Training Program}

Miyai et al. [35, 36] conducted two initial studies to investigate the effectiveness of a one month period of body weight-supported treadmill training (BWSTT) in PD patients (H\&Y 2.5 or 3). They found a greater improvement in the UPDRS, ambulation speed, and number of steps with BWSTT than with conventional physical therapy [35, 36]. Another study in PD patients (H\&Y 1-4) showed that improvements in dynamic posturography, number of falls during balance testing, Berg Balance, UPDRS, range of motion and gait were not related with the amount of body weight supported, since the treadmill training with additional weight bearing (5\% of body weight increase) led to the same improvements [37].

The gait improvements reported in the mentioned studies have been replicated and extended. Six weeks of intensive treadmill training, without body weight support, improved significantly the quality of life, motor UPDRS, gait speed and scores on the Short Physical Performance Battery (SPPB) in a group of 9 PD patients (H\&Y 1.5-3), [38]. However, stride time variability and swing time variability did not change significantly [38]. Other functional lower-limb tasks such as walking along a corridor, U-turn, turning around in a chair, standing on one foot, and standing up, were also improved after 6 weeks of treadmill training in PD patients [39]. Eight weeks of high intensity treadmill training with 10\% of body weight support increased gait speed, step and stride length, hip and ankle joint excursion and improved weight distribution during sit-to-stand in PD patients (H\&Y 1 or 2), [40].

Gait impairments such as freezing episodes and falls were also reduced as a result of treadmill training programs. On the treadmill, freezing episodes were less common and much briefer compared with overground walking [41]. In addition, when treadmill training is combined with conventional rehabilitation programs, such as those using sensory cues, the reduction of freezing episodes is greater than when these programs are used without treadmill training [42]. The treadmill has also been used to improve the balance in PD, in order to decrease falls $[43,44]$. In these studies the training included methods such as suddenly turning on and off the treadmill, with the patients standing facing forwards, backwards, or sideways [43].

Treadmill training has also been used to improve cardiorespiratory capacity in PD patients, since it is known that PD patients have lower levels of fitness [45]. Bergen et al. [46] showed improvements in PD patients in the aerobic capacity (VO2 peak) after a combined training of cycling and walking on the treadmill. However, in another study investigating aerobic treadmill training, although the subjects showed improvement in the peak ambulatory workload capacity, no changes were observed in the mean VO2 peak [47]. Recently, it has been shown that there is a decrease in oxygen uptake, heart and respiratory rates during the gait after treadmill training. These improvements become evident only during a graded exercise regime on the treadmill [48].

\subsection{Long Term Effects of a Treadmill Training Program}

One of the main goals of all rehabilitation programs is for the program to be effective even after it is completed. Long-term effects of treadmill programs have been reported by three studies [36-38]. A randomized trial showed that 4 weeks of BWSTT led to an improvement in the stride length that lasted for at least 3 months after the end of the program [36]. These long-term improvements were more stable in comparison with conventional physical therapy [36].

Another study showed that improvements in balance, gait, range of motion and motor UPDRS after four weeks of treadmill training were maintained for one month [37]. Similar results were reported by Herman et al. [38]. 


\subsection{Effects of One Treadmill Session}

The immediate effects of one treadmill session have been investigated. Miyai et al. [35] observed improvements in gait speed, five minutes after one session of weight-supported treadmill walking. Stride length and double stance duration was also improved after one training session on the treadmill [49]. Moreover, in these two studies, treadmill training was more effective than conventional gait therapy in improving gait parameters [35, 49].

Recently, improvements in gait speed were also found, 5 and 10 minutes after a 20 minutes treadmill gait session [50]. Although in this study the effects were similar in PD patients and control subjects, only the PD group with more severe symptoms increased the gait speed as a result of a improvement in the stride length after treadmill walking.

\subsection{PD Treadmill Gait Characteristics}

In order to understand the effect of the treadmill in the gait rehabilitation in PD patients it is necessary to determine the differences between the gait pattern over the treadmill in comparison with overground walking. Only two studies have explored this issue [50, 51].

When walking on the treadmill, both PD patients and healthy subjects reduced their gait variability, indicating a more stable gait pattern [51]. However, it seems that the adaptation on the treadmill is different depending on the severity of the disease. A group of advanced PD patients (H\&Y 3) improved their step length while walking on the treadmill in comparison with overground walking. However, the moderate PD group (H\&Y 2-2.5) showed comparable results to that of a healthy control group, showing no changes in gait during treadmill walking [50].

These results suggest that as the disease progresses PD patients can benefit from treadmill walking to a greater extent, in the improvement of gait. However, the question still remains, which are the mechanisms underlying these effects.

\section{Mechanisms implicated in treadmill gait benefits in PD}

The greater improvements following treadmill rehabilitation programs than conventional therapies in PD patients [35, 36, 49] suggest that there are mechanisms that are specific to the treadmill. Some of these mechanisms can be related with the different context in which the walking is performed and others with the features of the treadmill itself (see Table 1). 
Table 1. Summary of the Main Mechanisms Implicated in Treadmill Gait Benefits in PD

\begin{tabular}{|c|c|c|}
\hline Mechanism & Arguments to Support this Theory & Arguments to Question this Theory \\
\hline $\begin{array}{l}\text { Central Pattern } \\
\text { Generators }\end{array}$ & $\begin{array}{l}\text { Treadmill training could provide adequate sensory inputs, } \\
\text { which may stimulate the spinal locomotor circuitry [ } 53 \text {, } \\
\text { 55]. }\end{array}$ & $\begin{array}{l}\text { It is undetermined whether CPG is relevant in } \\
\text { the gait improvement of PD patients [35-37]. }\end{array}$ \\
\hline $\begin{array}{l}\text { External sensory } \\
\text { cues }\end{array}$ & $\begin{array}{l}\text { Treadmill walking provides propioceptive signals that may } \\
\text { be used by PD patients, triggering intact circuits and } \\
\text { bypassing the defective pallidocortical circuit, in order to } \\
\text { control movement. }\end{array}$ & $\begin{array}{l}\text { Changes in regional flow evaluated with } \\
\text { sPECT during treadmill walking, showed } \\
\text { absence of the lateral premotor cortex-parietal } \\
\text { overactivation that seems to accompany } \\
\text { externally triggered movements in Parkinson's } \\
\text { disease patients, indicating that treadmill- } \\
\text { walking has an internally driven mechanism } \\
\text { [75]. }\end{array}$ \\
\hline Visual feedback & $\begin{array}{l}\text { Modifications in the optical flow lead to modification in } \\
\text { the gait pattern [76, 77]. } \\
\text { Absence of visual flow may force the subject to look for } \\
\text { another source of visual information, as an anchor for } \\
\text { maintaining a stable position [78]. } \\
\text { PD patients can use attentional strategies and compensate } \\
\text { for the damaged automaticity [25]. The absence of visual } \\
\text { flow when walking on the treadmill could reduce } \\
\text { distraction and allow the patients to focus on the task. }\end{array}$ & $\begin{array}{l}\text { Only the absence of visual flow do not } \\
\text { increase the step length in PD patients [62]. }\end{array}$ \\
\hline $\begin{array}{l}\text { Imposed and } \\
\text { constant gait speed }\end{array}$ & $\begin{array}{l}\text { The constant speed of the treadmill could reduce the } \\
\text { degrees of freedom and help to minimize stride-to-stride } \\
\text { variations in gait timing [51]. }\end{array}$ & \\
\hline Hand support & $\begin{array}{l}\text { Walking aids that have hand support, can improve balance } \\
\text { and mobility in older adults and people with other clinical } \\
\text { conditions [83]. }\end{array}$ & $\begin{array}{l}\text { PD patients reduce their speed and stride } \\
\text { length when they walk with a wheeled walker } \\
\text { in comparison with normal gait }[51,84] \text {. }\end{array}$ \\
\hline $\begin{array}{l}\text { Improvements in } \\
\text { aerobic fitness and } \\
\text { strength }\end{array}$ & $\begin{array}{l}\text { Aerobic and resistance training programs improve gait in } \\
\text { PD patients }[87,88] \text {. }\end{array}$ & $\begin{array}{l}\text { Treadmill training improve balance and gait in } \\
\text { PD patients without strength modifications in } \\
\text { the lower limbs [37]. }\end{array}$ \\
\hline
\end{tabular}

\subsection{Central Pattern Generators for Locomotion}

The term of Central Pattern Generator (CPG) refers to neuronal circuits that can produce rhythmic movements when isolated from the brain or independent of sensory input. In cats, it is assumed that there is at least one such CPG for each limb and that these CPGs are mainly located within the thoraco-lumbar region [52]. Research in cats has revealed that locomotor CPG is regulated by descendent supraspinal signals and afferent input of the limbs. Afferents probably originate from proprioceptive receptors of extensor muscles (Golgi tendon organs and muscle spindles) and mechanoreceptors in the foot. There are other afferents that signal hip position and probably originate from the hip joint and from the muscles around the hip [53].

The CPG involves an extensor and flexor half-centre, which are mutually inhibited. In the stance phase, load is detected by Golgi tendon organs, muscle spindles of extensor muscles and cutaneous afferents of the foot which activate the extensor half-centre. Muscle spindles afferents of the flexor muscle excite the flexor half-centre at the end of the stance phase, and initiate the swing phase [53, 54]

In humans, there is only indirect evidence of the existence of spinal CPG. The contribution of CPG to the human gait remains an important question $[55,56]$. The positive effect of the treadmill in cats and humans with a spinal lesion has been attributed to the activation of the CPG (Dietz et al., 1997; Van de Crommert et al., 1998; Dietz and Colombo, 2004). The belt of the treadmill could force the subject to step, through stretch facilitation of hip flexors and ankle plantar flexors at the end of the stance phase [57]. In this way, treadmill training could provide adequate sensory inputs, such as hip extension, which may stimulate the spinal locomotor circuitry [53, 55]. In healthy individuals it has been shown that treadmill walking increases hip extensor movements [58] and decreases CV of the stance period [59] compared with walking overground. On the treadmill, the lower limbs are automatically and regularly pulled back; therefore, it is conceivable that afferents of muscle spindles, Golgi tendon organs and cutaneous sensors are sending impulses to the CPG, resulting in a regular walking pattern [59]

It is undetermined whether CPG is relevant in the gait improvement of PD patients [35-37]. In PD patients the tibial activation is increased during the swing phase together with a poor leg extensor 
activation, due to a lower load sensitivity, compared with healthy subjects [60]. The origin of this may be an impaired extensor suppression of the flexor generating circuitry [61]. It is possible that the PD patients take advantage of the hip extension over the treadmill. Unfortunately, no biomechanic data are available to confirm this hypothesis. A recent study confirms that improvements in stride length in PD are due to the belt movement itself, probably due to propioceptive afferents generated by the belt displacement [62]. However, proprioceptive signals may act as external cues, using different cortical pathways, and thus bypassing the deteriorated nigrostriatal pathway.

\subsection{External Sensory Cues}

A series of studies have revealed that PD patients can generate a normal gait pattern in the presence of adequate regulatory sensory stimulation. It has been suggested that external sensory cues can provide the necessary trigger in PD to switch from one movement component, to the next, bypassing defective internal pallidocortical projections, possibly via the lateral premotor cortex, which controls externally guided movements [63-65]. Visual cues placed on the floor at the desired step length, or rhythmic auditory cues can assist with gait initiation and execution, improving the gait pattern in PD [66-72]. Although propioceptive cues have not been extensively investigated, it has been shown that stepsynchronized vibration stimulation of the soles, during walking, improves gait speed, stride length and variability in PD [73]. Frenkel-Toledo et al. [51] showed that PD patients walk on the treadmill with a reduced stride time variability in comparison with walking overground, suggesting that the treadmill provides external cues to reduce gait variability. It has been suggested that a moving walkway provides external cueing that is mediated through propioceptive receptors [74].

Treadmill walking provides propioceptive signals that may be used by PD patients, triggering intact circuits and bypassing the defective pallidocortical circuit, in order to control movement. However, changes in regional flow evaluated with sPECT during treadmill walking, showed absence of the lateral premotor cortex-parietal overactivation that seems to accompany externally triggered movements in Parkinson's disease patients, indicating that treadmillwalking has an internally driven mechanism [75].

\subsection{Visual Feedback}

Another possible set of explanations for the treadmill effects is related with the visual information provided by the treadmill. The source of the visual information is related with the optical flow and with the distance to the front of the treadmill.

When walking over treadmill, subjects must adapt the execution of forward walking movements to zero optical flow. It has been shown that modifications in the optical flow lead to modification in the gait pattern. For instance, backward optical flow results in a decrease of gait speed, while the opposite effect is found with forward optical flow [76]. However, it seems that this optical flow effect is different for healthy control subjects and PD patients, which could explain the different adaptation to the treadmill in the two groups [77].

The effect of the optical flow while walking on the treadmill could also have other effects on PD gait. First, it may force the subject to look for another source of visual information, as an anchor for maintaining a stable position [78] and second, it could reduce distraction and allow the patients to focus on the task.

Regarding the first point, it is known that PD patients compensate for the deficits in proprioception by visual kinesthesia, causing predominance of visual control and exaggerated reaction to visual feedback $[52,79]$. Thus, it could be possible that while the patients are walking on the treadmill they use the distance from the front of the treadmill as a static visual cue [50]. This cue could provide constant visual feedback regarding the position of the body, and the gait can be guided externally rather than internally, as in overground walking. However, a recent study showed that this visual feedback is not the main mechanism implicated in the step length increase in PD patients during treadmill walking [62].

In relation to the second point, it is known that in some conditions visual information may disrupt locomotion and induce freezing (for example passing through a door) [80], thus the absence of visual flow when walking on the treadmill could reduce distraction and allow the patients to focus on the task. This is a crucial point since attention plays an important role in PD gait [28, 81]. To generate appropriate stride length, PD patients can use attentional strategies and compensate for the damaged automaticity [25]. Environmental factors, which compete for attention, may increase the difficulty of attending to gait and, as a result, decrease mobility and further increase the risk of falls [82]. Thus, walking on the treadmill can be a more optimal condition for the PD patients to generate a normal gait pattern compared to walking overground. 


\subsection{Other Mechanims}

It has been suggested that decreased gait variability on the treadmill may be due to the imposed and constant gait speed [51]. The constant speed of the treadmill could reduce the degrees of freedom and help to minimize stride-to-stride variations in gait timing [51]. During overground walking there are ongoing and unconstrained fluctuations in gait speed, but on the treadmill, patients must match their pace to one constant speed [74]. This hypothesis has been recently confirmed by Bello et al. [62], showing that PD patients improved their gait double support time variability when walking on the treadmill and overground, following a machine that moves in a fixed speed. However, in both conditions the patients had handrail support. When they followed the machine without handrail support, both controls and PD patients increased their variability, suggesting a greater degree of difficulty in accomplishing the task.

Walking aids that have hand support, like canes and walkers, can improve balance and mobility in older adults and people with other clinical conditions [83]. Many treadmill studies in PD do not report whether the patients hold their hands on the handrails. However, some untrained subjects may not be able to walk on a treadmill without holding on to the handrails [51]. Two investigations have shown that PD patients reduce their speed and stride length when they walk with a wheeled walker in comparison with normal gait $[51,84]$. These results could suggest that the hand support over the treadmill may not be the mechanism underlying the gait improvements. However, treadmill gait and walker gait are different because the patients have to pull and control the walker. Bateni and Maki [83] suggested that walking aids can provide mechanical advantages as well as somatosensory feedback. Tactile somatosensory information from the hand can contribute to postural stabilization $[85,86]$. On the treadmill, somatosensory fingertip input from an external reference provides spatial orientation in healthy subjects, which, sustains body stability [78]. Thus, the handrail support may work as an external cue.

Improvements in aerobic fitness and strength could explain gait improvements after a treadmill training program. It has been shown that gait improves after aerobic and resistance training programs in PD patients $[87,88]$. A recent pilot study demonstrated that treadmill training improves the metabolic walking economy in PD and that this improvement is associated with the trained motor activity, since no changes in metabolic parameters were observed on a cycloergometer [48]. However, fitness improvements cannot explain the benefits from one session of treadmill training. Moreover, after 6 weeks of treadmill training programs, PD patients showed improvements in balance and gait without strength modifications in the lower limbs [37].

Another explanation for the treadmill improvements is related with the assumption that treadmill gait could induce motor learning in PD [38, 40,43]. This could explain why the improvement in gait is sustained several months after the treadmill training is completed [38]. A recent study reported normalization of corticomotor excitability after highintensity exercise as well gait improvements in early PD [40]. The improvements were diminished when the exercise intensity used was low. These findings suggest that intensity may be an important exercise parameter for facilitating activity- dependent neuroplasticity, which is associatiated with improved motor performance [40]. The motor learning induced by the treadmill training could also be mediated by the CPG, since learning occurs at the spinal level [53].

\section{Conclusions}

Ten years have passed since the first treadmill training study in PD patients. Since then, several studies have shown that the treadmill is a promising tool in the rehabilitation of gait in PD. Long term and short term benefits have confirmed the therapeutic use of the treadmill in the restoration of the impaired gait pattern in PD patients. When walking on the treadmill, PD patients are able to perform more stable and longer steps compared to when they walk on the ground. However, more studies must be conducted in order to explore the optimal parameters (speed, duration) for an effective treadmill training program.

Another important issue that must be addressed is the mechanisms underlying the treadmill effect. Understanding these mechanisms could improve the prescription and efficacy of the physical therapy in PD.

\section{Financial disclosure/conflict of interest}

This work was supported by Ministerio de Ciencia e Innovación (PSI2008-03175) and Xunta de Galicia (2009/002), Spain. All authors have no conflict of interest and no further financial disclosure to make. 


\section{Acknowledgments}

We thank Noa Fogelson for the revision of the manuscript.

\section{References}

[1] Jenkins R. A Elizabethan Human-Power Engine: John Payne and the History of the Treadmill. In: Jenkins R, Society N, Eds. Links in the history of engineering and technology from Tudor times; the collected papers of Rhys Jenkins Comprising articles in the professional and technical press mainly prior to 1920 and a catalogue of other published work. Freeport, N.Y.: Books for Libraries Press 1971; pp. 1-8.

[2] Yu PN, Bruce RA, Lovejoy FW, McDowell ME. Variations in electrocardiographic responses during exercise; studies of normal subjects under unusual stresses and of patients with cardiopulmonary diseases. Circulation 1951; 3(3): 368-76.

[3] Bruce RA. Evaluation of functional capacity and exercise tolerance of cardiac patients. Mod Concepts Cardiovasc Dis 1956; 25(4): 321-6.

[4] Bruce RA, Blackmon JR, Jones JW, Strait G. Exercising Testing in Adult Normal Subjects and Cardiac Patients. Pediatrics 1963; 32(suppl): 742-56.

[5] Barbeau H, Rossignol S. Recovery of locomotion after chronic spinalization in the adult cat. Brain Res 1987; 412(1): 84-95.

[6] Edgerton VR, Roy RR, Hodgson JA, Prober RJ, de Guzman CP, de Leon R. Potential of adult mammalian lumbosacral spinal cord to execute and acquire improved locomotion in the absence of supraspinal input. J Neurotrauma 1992; 9 (suppl 1): S119-28.

[7] Hodgson JA, Roy RR, de Leon R, Dobkin B, Edgerton VR. Can the mammalian lumbar spinal cord learn a motor task? Med Sci Sports Exerc 1994; 26(12): 1491-7.

[8] Lovely RG, Gregor RJ, Roy RR, Edgerton VR. Weight-bearing hindlimb stepping in treadmill-exercised adult spinal cats. Brain Res 1990; 514(2): 206-18.

[9] Barbeau H, Rossignol S. Enhancement of locomotor recovery following spinal cord injury. Curr Opin Neurol 1994; 7(6): 517-24

[10] Dietz V, Colombo G, Jensen L. Locomotor activity in spinal man. Lancet 1994; 344(8932): 1260-3.

[11] Dietz V, Colombo G, Jensen L, Baumgartner L. Locomotor capacity of spinal cord in paraplegic patients. Ann Neurol 1995; 37(5): 574-82.

[12] Wernig A, Muller S. Laufband locomotion with body weight support improved walking in persons with severe spinal cord injuries. Paraplegia 1992; 30(4): 229-38.

[13] Wernig A, Muller S, Nanassy A, Cagol E. Laufband therapy based on 'rules of spinal locomotion' is effective in spinal cord injured persons. Eur J Neurosci 1995; 7(4): 823-9.

[14] Dobkin BH, Harkema S, Requejo P, Edgerton VR. Modulation of locomotor-like EMG activity in subjects with complete and incomplete spinal cord injury. J Neurol Rehabil 1995; 9(4): 183-90.

[15] Fahn S, Elton RL. Unified Parkinson's Disease Rating Scale. In: Fahn S, Marsden CD, Goldstein M, Calne DB, Eds. Recent developments in Parkinson's disease. Florham Park, NJ: Macmillan Healthcare Information 1987; pp. 153-63.

[16] Hoehn MM, Yahr MD. Parkinsonism: onset, progression and mortality. Neurology 1967; 17(5): 427-42.

[17] Rahman S, Griffin HJ, Quinn NP, Jahanshahi M. Quality of life in Parkinson's disease: the relative importance of the symptoms. Mov Disord 2008; 23(10): 1428-34.

[18] Brozova H, Stochl J, Roth J, Ruzicka E. Fear of falling has greater influence than other aspects of gait disorders on quality of life in patients with Parkinson's disease. Neuro Endocrinol Lett 2009; 30(4): 453-7.

[19] Morris ME, Iansek R, Matyas TA, Summers JJ. Ability to modulate walking cadence remains intact in Parkinson's disease. J Neurol Neurosurg Psychiatry 1994; 57(12): 1532-4.

[20] Sofuwa O, Nieuwboer A, Desloovere K, Willems AM, Chavret F, Jonkers I. Quantitative gait analysis in Parkinson's disease: comparison with a healthy control group. Arch Phys Med Rehabil 2005; 86(5): 1007-13.

[21] Morris ME, Iansek R, Matyas TA, Summers JJ. The pathogenesis of gait hypokinesia in Parkinson's disease. Brain 1994; 117(5): 1169-81.

[22] Fernandez del Olmo M, Cudeiro J. A simple procedure using auditory stimuli to improve movement in Parkinson's disease: a pilot study. Neurol Clin Neurophysiol 2003; 2003(2): 1-7.

[23] Hausdorff JM, Cudkowicz ME, Firtion R, Wei JY, Goldberger AL. Gait variability and basal ganglia disorders: stride-to-stride variations of gait cycle timing in Parkinson's disease and Huntington's disease. Mov Disord 1998; 13(3): 428-37.

[24] Lewis GN, Byblow WD, Walt SE. Stride length regulation in Parkinson's disease: the use of extrinsic, visual cues. Brain 2000; 123(10): 2077-90.

[25] Morris ME, Iansek R, Matyas TA, Summers JJ. Stride length regulation in Parkinson's disease. Normalization strategies and underlying mechanisms. Brain 1996; 119(2): 551-68.

[26] Blin O, Ferrandez AM, Pailhous J, Serratrice G. Dopa-sensitive and dopa-resistant gait parameters in Parkinson's disease. J Neurol Sci 1991; 103(1): 51-4

[27] Bloem BR, van Vugt JP, Beckley DJ. Postural instability and falls in Parkinson's disease. Adv Neurol 2001; 87: 209-23.

[28] Hausdorff JM, Balash J, Giladi N. Effects of cognitive challenge on gait variability in patients with Parkinson's disease. J Geriatr Psychiatry Neurol 2003; 16(1): 53-8. 
[29] Hausdorff JM, Rios DA, Edelberg HK. Gait variability and fall risk in community-living older adults: a 1-year prospective study. Arch Phys Med Rehabil 2001; 82(8): 1050-6.

[30] Maki BE. Gait changes in older adults: predictors of falls or indicators of fear. J Am Geriatr Soc 1997; 45(3): 313-20.

[31] Schaafsma JD, Giladi N, Balash Y, Bartels AL, Gurevich T, Hausdorff JM. Gait dynamics in Parkinson's disease: relationship to Parkinsonian features, falls and response to levodopa. J Neurol Sci 2003; 212(1-2): 47-53.

[32] Aita JF. Why patients with Parkinson's disease fall. JAMA 1982; 247(4): 515-6.

[33] Giladi N, McMahon D, Przedborski S, Flaster E, Guillory S, Kostic V, et al. Motor blocks in Parkinson's disease. Neurology 1992; 42(2): 333-9.

[34] Giladi N, Balash Y. The clinical approach to gait disturbances in Parkinson's disease; maintaining independent mobility. J Neural Transm Suppl 2006; 70: 327-32.

[35] Miyai I, Fujimoto Y, Ueda Y, Yamamoto H, Nozaki S, Saito T, et al. Treadmill training with body weight support: its effect on Parkinson's disease. Arch Phys Med Rehabil 2000; 81(7): 849-52.

[36] Miyai I, Fujimoto Y, Yamamoto H, Ueda Y, Saito T, Nozaki S, et al. Long-term effect of body weight-supported treadmill training in Parkinson's disease: a randomized controlled trial. Arch Phys Med Rehabil 2002; 83(10): 1370-3.

[37] Toole T, Maitland CG, Warren E, Hubmann MF, Panton L. The effects of loading and unloading treadmill walking on balance, gait, fall risk, and daily function in Parkinsonism. NeuroRehabilitation 2005; 20(4): 307-22.

[38] Herman T, Giladi N, Gruendlinger L, Hausdorff JM. Six weeks of intensive treadmill training improves gait and quality of life in patients with Parkinson's disease: a pilot study. Arch Phys Med Rehabil 2007; 88(9): 1154-8.

[39] Kurtais Y, Kutlay S, Tur BS, Gok H, Akbostanci C. Does treadmill training improve lower-extremity tasks in Parkinson disease? A randomized controlled trial. Clin J Sport Med 2008; 18(3): 289-91.

[40] Fisher BE, Wu AD, Salem GJ, Song J, Lin CH, Yip J, et al. The effect of exercise training in improving motor performance and corticomotor excitability in people with early Parkinson's disease. Arch Phys Med Rehabil 2008; 89(7): 1221-9.

[41] Snijders AH, Weerdesteyn V, Hagen YJ, Duysens J, Giladi N, Bloem BR. Obstacle avoidance to elicit freezing of gait during treadmill walking. Mov Disord 2010; 25(1): 57-63.

[42] Frazzitta G, Maestri R, Uccellini D, Bertotti G, Abelli P. Rehabilitation treatment of gait in patients with Parkinson's disease with freezing: a comparison between two physical therapy protocols using visual and auditory cues with or without treadmill training. Mov Disord 2009; 24(8): 1139-43.

[43] Protas EJ, Mitchell K, Williams A, Qureshy H, Caroline K, Lai EC. Gait and step training to reduce falls in Parkinson's disease. NeuroRehabilitation 2005; 20(3): 183-90.

[44] Cakit BD, Saracoglu M, Genc H, Erdem HR, Inan L. The effects of incremental speed-dependent treadmill training on postural instability and fear of falling in Parkinson's disease. Clin Rehabil 2007; 21(8): 698-705.

[45] Jain SS, DeLisa JA. Degenerative central nervous system diseases. In: Felsental G, Garrison SJ, Steinberg FU, Eds. Rehabilitation of the aging and ederly patient. Baltimore: Willians \& Wilkins 1994; p. 220.

[46] Bergen JL, Toole T, Elliott RG, 3rd, Wallace B, Robinson K, Maitland CG. Aerobic exercise intervention improves aerobic capacity and movement initiation in Parkinson's disease patients. NeuroRehabilitation 2002; 17(2): 161-8.

[47] Skidmore FM, Patterson SL, Shulman LM, Sorkin JD, Macko RF. Pilot safety and feasibility study of treadmill aerobic exercise in Parkinson disease with gait impairment. J Rehabil Res Dev 2008; 45(1): 117-24.

[48] Pelosin E, Faelli E, Lofrano F, Avanzino L, Marinelli L, Bove M, et al. Effects of treadmill training on walking economy in Parkinson's disease: a pilot study. Neurol Sci 2009; 30: 499-504

[49] Pohl M, Rockstroh G, Ruckriem S, Mrass G, Mehrholz J. Immediate effects of speed-dependent treadmill training on gait parameters in early Parkinson's disease. Arch Phys Med Rehabil 2003; 84(12): 1760-6.

[50] Bello O, Sanchez JA, Fernandez-del-Olmo M. Treadmill walking in Parkinson's disease patients: adaptation and generalization effect. Mov Disord 2008; 23(9): 1243-9.

[51] Frenkel-Toledo S, Giladi N, Peretz C, Herman T, Gruendlinger L, Hausdorff JM. Treadmill walking as an external pacemaker to improve gait rhythm and stability in Parkinson's disease. Mov Disord 2005; 20(9): 110914.

[52] Dietz V. Spinal cord pattern generators for locomotion. Clin Neurophysiol 2003; 114(8): 1379-89.

[53] Van de Crommert HW, Mulder T, Duysens J. Neural control of locomotion: sensory control of the central pattern generator and its relation to treadmill training. Gait Posture 1998; 7(3): 251-63.

[54] Pearson KG. Proprioceptive regulation of locomotion. Curr Opin Neurobiol 1995; 5(6): 786-91.

[55] Duysens J, Van de Crommert HW. Neural control of locomotion; The central pattern generator from cats to humans. Gait Posture 1998; 7(2): 131-41.

[56] MacKay-Lyons M. Central pattern generation of locomotion: a review of the evidence. Phys Ther 2002; 82(1): 69-83.

[57] Shepherd RC, J. . Treadmill walking in neurorehabilitation. Neurorehabil Neural Repair 1999; 13(3): 171-3.

[58] Lee SJ, Hidler J. Biomechanics of overground vs. treadmill walking in healthy individuals. J Appl Physiol 2008; 104(3): 747-55.

[59] Warabi T, Kato M, Kiriyama K, Yoshida T, Kobayashi N. Treadmill walking and overground walking of human subjects compared by recording sole-floor reaction force. Neurosci Res 2005; 53(3): 343-8.

[60] Dietz V, Colombo G. Influence of body load on the gait pattern in Parkinson's disease. Mov Disord 1998; 13(2): 255-61.

[61] Dietz V, Duysens J. Significance of load receptor input during locomotion: a review. Gait Posture 2000; 11(2): $102-10$. 
[62] Bello O, Marquez G, Camblor M, Fernandez-Del-Olmo M. Mechanisms involved in treadmill walking improvements in Parkinson's disease. Gait Posture 2010; 32(1): 118-23.

[63] Brooks DJ. Functional imaging studies in Parkinson's disease. In: Lewitt P, Oertel W, Eds. Parkinson's disease The treatment options. London: Martin Dunitz 1999; pp. 21-38.

[64] Cunnington R, Iansek R, Bradshaw JL, Phillips JG. Movementrelated potentials in Parkinson's disease. Presence and predictability of temporal and spatial cues. Brain 1995; 118(4): 935-50.

[65] Passingham RE. Premotor cortex and the retrieval of movement. Brain Behav Evol 1989; 33(2-3): 189-92.

[66] Azulay JP, Van Den Brand C, Mestre D, Blin O, Sangla I, Pouget J, et al. Automatic motion analysis of gait in patients with Parkinson disease: effects of levodopa and visual stimulations. Rev Neurol (Paris) 1996; 152(2): 128-34.

[67] Enzensberger W, Fischer PA. Metronome in Parkinson's disease. Lancet 1996; 347(9011): 1337.

[68] Lewis GN, Byblow WD, Walt SE. Stride length regulation in Parkinson's disease: the use of extrinsic, visual cues. Brain 2000; 123 (Pt 10): 2077-90.

[69] Martin JP. The basal ganglia and posture. London: Pitman 1967.

[70] McIntosh GC, Brown SH, Rice RR, Thaut MH. Rhythmic auditory- motor facilitation of gait patterns in patients with Parkinson's disease. J Neurol Neurosurg Psychiatry 1997; 62(1): 22-6.

[71] Morris ME, Iansek R, Matyas TA, Summers JJ. The pathogenesis of gait hypokinesia in Parkinson's disease. Brain 1994; 117 (Pt 5): 1169-81.

[72] Thaut MH, McIntosh GC, Rice RR, Miller RA, Rathbun J, Brault JM. Rhythmic auditory stimulation in gait training for Parkinson's disease patients. Mov Disord 1996; 11(2): 193-200.

[73] Novak P, Novak V. Effect of step-synchronized vibration stimulation of soles on gait in Parkinson's disease: a pilot study. J Neuroeng Rehabil 2006; 3: 9.

[74] Herman T, Giladi N, Hausdorff JM. Treadmill training for the treatment of gait disturbances in people with Parkinson's disease: a mini-review. J Neural Transm 2009; 116(3): 307-18.

[75] Hanakawa T, Katsumi Y, Fukuyama H, Honda M, Hayashi T, Kimura J, et al. Mechanisms underlying gait disturbance in Parkinson's disease: a single photon emission computed tomography study. Brain 1999; 122(7): 1271-82.

[76] Prokop T, Schubert M, Berger W. Visual influence on human locomotion. Modulation to changes in optic flow. Exp Brain Res 1997; 114(1): 63-70.

[77] Ferrarin M, Rabuffetti M, Tettamanti M, Pignatti R, Mauro A, Albani G. Effect of optical flow versus attentional strategy on gait in Parkinson's Disease: a study with a portable optical stimulating device. J Neuroeng Rehabil 2008; $5: 3$.

[78] Dickstein R, Laufer Y. Light touch and center of mass stability during treadmill locomotion. Gait Posture 2004; 20(1): 41-7.

[79] Schubert M, Prokop T, Brocke F, Berger W. Visual kinesthesia and locomotion in Parkinson's disease. Mov Disord 2005; 20(2): 141- 50.

[80] Azulay JP, Mesure S, Blin O. Influence of visual cues on gait in Parkinson's disease: contribution to attention or sensory dependence? J Neurol Sci 2006; 248(1-2): 192-5.

[81] Canning CG. The effect of directing attention during walking under dual-task conditions in Parkinson's disease. Parkinsonism Relat Disord 2005; 11(2): 95-9.

[82] Rochester L, Hetherington V, Jones D, Nieuwboer A, Willems AM, Kwakkel G, et al. Attending to the task: interference effects of functional tasks on walking in Parkinson's disease and the roles of cognition, depression, fatigue, and balance. Arch Phys Med Rehabil 2004; 85(10): 1578-85.

[83] Bateni H, Maki BE. Assistive devices for balance and mobility: benefits, demands, and adverse consequences. Arch Phys Med Rehabil 2005; 86(1): 134-45.

[84] Cubo E, Moore CG, Leurgans S, Goetz CG. Wheeled and standard walkers in Parkinson's disease patients with gait freezing. Parkinsonism Relat Disord 2003; 10(1): 9-14.

[85] Jeka JJ. Light touch contact as a balance aid. Phys Ther 1997; 77(5): 476-87.

[86] Jeka JJ, Lackner JR. Fingertip contact influences human postural control. Exp Brain Res 1994; 100(3): 495-502.

[87] Scandalis TA, Bosak A, Berliner JC, Helman LL, Wells MR. Resistance training and gait function in patients with Parkinson's disease. Am J Phys Med Rehabil 2001; 80(1): 38-43.

[88] Sage MD, Almeida QJ. Symptom and gait changes after sensory attention focused exercise vs aerobic training in Parkinson's disease. Mov Disord 2009; 24(8): 1132-8. 